\title{
Correction to: C3aR signaling and gliosis in response to neurodevelopmental damage in the cerebellum
}

Kevin G. Young ${ }^{1,2}$, Keqin Yan ${ }^{1}$ and David J. Picketts ${ }^{1,3,4^{*}}$

\section{Correction to: J Neuroinflammation}

https://doi.org/10.1186/s12974-019-1530-4

Following publication of the original article [1], the authors noticed missing labels in Fig. 1a. The bar graph contains the labels C3, C2, C1ql2, C1ql1, C1qb, GFAP, and VGF. However, the labels should be C3, C4b, C2, C3aR1, C1q12, C1q14, C1ql1, C1qa, C1qb, C1qc, GFAP, USP18, and VGF. The correct version of Fig. 1a is published in this Erratum.

\footnotetext{
Author details

'Regenerative Medicine Program, Ottawa Hospital Research Institute, Ottawa, ON K1H 8L6, Canada. ${ }^{2}$ Present Address: Therapeutic Products Directorate, Health Canada, 1600 Scott St, Ottawa, ON K1A OK9, Canada. ${ }^{3}$ Department of Cellular and Molecular Medicine, University of Ottawa, Ottawa, ON K1H 8M5, Canada. ${ }^{4}$ Department of Biochemistry, Microbiology, and Immunology, University of Ottawa, Ottawa, ON K1H 8M5, Canada.
}

Published online: 23 January 2020

\author{
References \\ 1. Young KG, Yan, K, Picketts DJ. C3aR signaling and gliosis in response to \\ neurodevelopmental damage in the cerebellum. J Neuroinflammation. \\ 2019;16:135. https://doi.org/10.1186/s12974-019-1530-4.
}

\footnotetext{
The original article can be found online at https://doi.org/10.1186/s12974019-1530-4

* Correspondence: dpicketts@ohri.ca

${ }^{1}$ Regenerative Medicine Program, Ottawa Hospital Research Institute, Ottawa, ON K1H 8L6, Canada

${ }^{3}$ Department of Cellular and Molecular Medicine, University of Ottawa,

Ottawa, ON K1H 8M5, Canada

Full list of author information is available at the end of the article
}

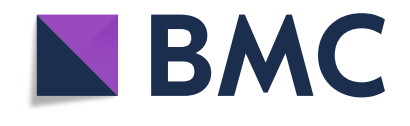

(c) The Author(s). 2020 Open Access This article is distributed under the terms of the Creative Commons Attribution 4.0 International License (http://creativecommons.org/licenses/by/4.0/), which permits unrestricted use, distribution, and reproduction in any medium, provided you give appropriate credit to the original author(s) and the source, provide a link to the Creative Commons license, and indicate if changes were made. The Creative Commons Public Domain Dedication waiver (http://creativecommons.org/publicdomain/zero/1.0/) applies to the data made available in this article, unless otherwise stated. 


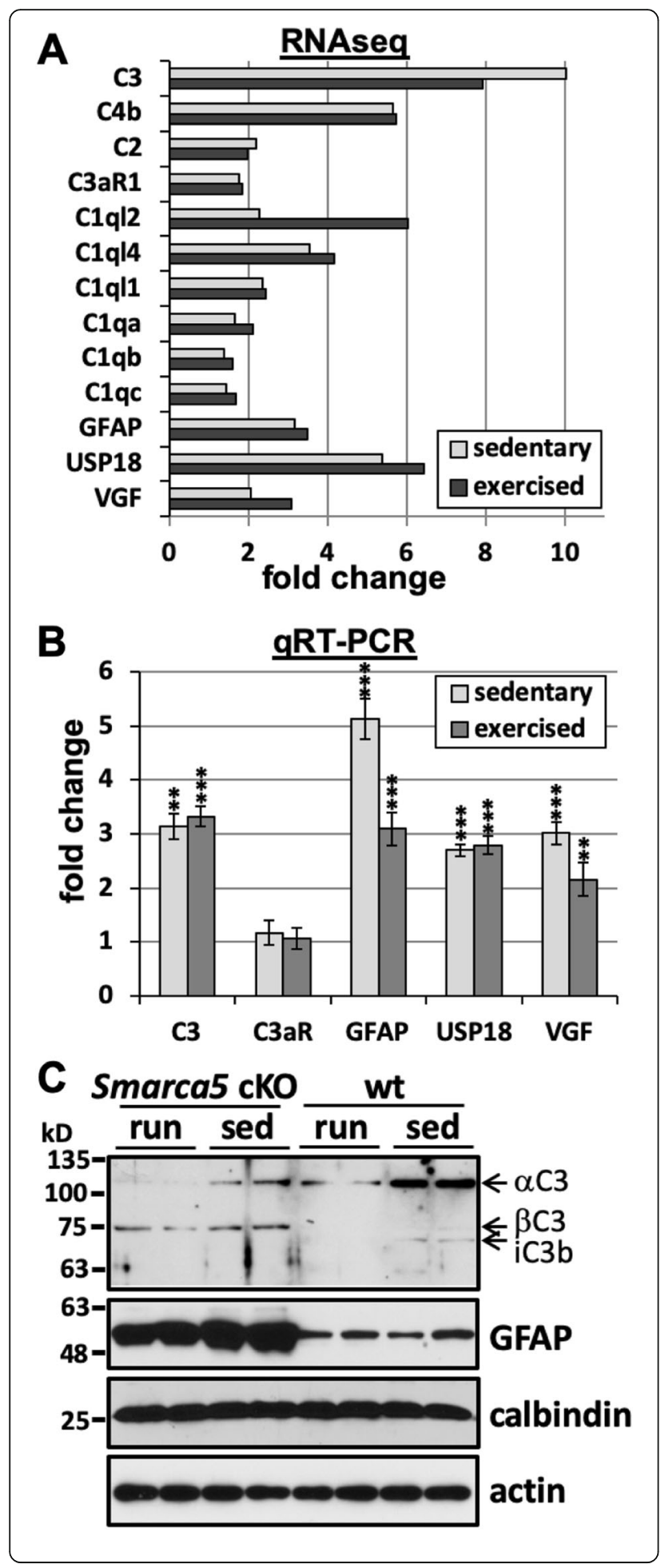

Fig. 1 Altered C3 complement protein expression in the Smarca5 cKO cerebellum of exercised and sedentary mice. Increases in mRNA transcripts coding for complement, complement-related proteins, and inflammation-related proteins in the Smarca5 CKO cerebellum, as indicated by RNAseq analysis (a). Fold changes are shown for the Smarca5 CKO groups (sedentary or exercised) relative to corresponding wild-type groups. qRT-PCR analysis confirmed the increases in C3, GFAP, USP18, and VGF (b), though the magnitudes of these increases varied from the RNAseq data set. Shown are the fold changes in the Smarca5 CKO cerebellum relative to wild-type littermates ( $n=3$ in each of the four groups of wild-type exercised (run) or sedentary (sed), and mutant exercised or sedentary animals; differences relative to wild-type littermates are noted with ${ }^{* *} p<$ 0.005 and $\left.{ }^{* * *} p<0.001\right)$. No increase was observed for the C3a receptor, C3aR. Protein analysis demonstrated a clear increase in GFAP expression in Smarca5 cKO cerebellum samples (c). C3 protein expression was also altered in the Smarca5 CKO cerebellum. The C $3 a$ chain was less prominent relative to the C $3 \beta$ chain in Smarca5 cKO cerebellum samples compared to wild-type samples. Blotting results are representative of similar results from four mice/group 